\title{
Language, Listening and Learning: Critically Reflective Accountability for INGOs
}

\begin{abstract}
This paper examines the emergence of two waves of reforms across the international NGO (INGO) sector in accountability discourse and practice. The first wave accountability model was narrowly framed around the demands of powerful stakeholders such as donors and governments, whereas the second wave was a more holistic approach that prioritised the obligations of INGOs towards their 'beneficiaries'. It is argued that INGOs should embed critically reflective accountability by pursuing further reforms in three thematic areas. Firstly, words like 'beneficiary' should be expunged from the language of accountability, since it is encoded with norms that implicitly undermine the rights of people and communities to expect that INGOs should be answerable for their actions. Secondly, listening to marginalised stakeholders should be facilitated by inclusive discursive arenas that enable and empower people 'to speak and be heard'. Lastly, INGOs need to use feedback to become a learning organisation, and collaborate with peers to engender a culture of reflective learning across the sector.
\end{abstract}

\section{Points for Practitioners}

The paper offers several policy recommendations structured around the three core themes of the paper. These include suggestions for the training of field-staff, issues concerning the design of participatory exercises, and proposals for a strengthened regime of peer-regulation.

\section{Key Words}

Accountability, civil society, development, regulation, INGO.

Fifteen years ago, in a widely cited article, Jessica Mathews heralded a 'power shift' in politics from nation-states to non-state actors, exemplified by the 'unprecedented influence' of NGOs (1997). What then seemed like a contentious statement is now a commonplace observation. The increased leverage of INGOs on the world stage has led some to raise serious concerns about their credibility as actors of conscience, claiming that they are not sufficiently answerable to those that they claim to represent and serve (Anderson \& Reiff, 2004). Indeed, the One World Trust has found in comparative surveys that several INGOs score less well on basic measures of accountability than organisations that are popular targets of INGO censure, such as the World Bank and Royal Dutch Shell (Blagescu \& Lloyd, 2006; Lloyd et al., 2008).

Some prominent INGOs have responded to these criticisms with concerted efforts to address their accountability deficits through a variety of mechanisms, including peer regulation and community consultations. The emergent INGO accountability regime signals recognition in the sector that it is imperative to re-establish its credentials and legitimacy if it is to continue to occupy a privileged position in international politics. It has been noted that these reforms have not attracted much academic attention; an odd omission in an otherwise lively field of research (Collingwood \& Logister, 2005: 176; Piewitt et al., 2010: 239). The relevant scholarly work that does exist tends to be clustered in development studies, or in the accounting and auditing literature (e.g. Ebrahim, 2003a; Jordan \& Van Tuijl, 2000; Kilby, 2006; O'Dwyer \& Unerman, 2008, 2010). International public administration would seem to be the ideal disciplinary base to further develop academic expertise in INGO accountability. It is uniquely placed to house research into different dimensions of the topic, such as empirical analysis of the functioning of the policy process, normative critiques of decisionmaking; and comparative case studies of INGO governance in different countries. This article aims to 
promote interest in INGO accountability amongst scholars in the administrative sciences by proposing a theoretical framework to orientate future empirical research. It outlines a typology to aid conceptualisation of the different modalities of INGO accountability, and introduces the categories of commission accountability and dialogic accountability to the literature, which capture important aspects of an INGOs' relationship with its stakeholders. The typology provides a framework for the latter half of the article, which critiques current practice and proposes an agenda for change.

The article proceeds as follows. First, it defines key terms and considers the drivers for INGO reform. Second, it discusses early attempts by INGOs to improve their accountability, which tended to privilege the demands of powerful stakeholders such as donors and governments. Third, it examines how this bias was addressed by a subsequent wave of reforms, which reinforced the responsibilities of INGOs towards their 'beneficiaries', their staff and members, and peer organisations. Fourth, it proposes specific policy reforms, separated into the themes of language, listening and learning. For example, it is suggested that the term 'beneficiaries' is replaced by 'primary stakeholder' (i.e. language); that aid workers undertake periodic critical reflection of their personal role in reproducing power disparities between the INGO and communities (listening); that a 'gold standard' award is introduced to recognise good accountability practice, and that staff are encouraged to use a variety of formal and informal networking opportunities (learning). The paper concludes by arguing in favour of a critically reflective model of accountability, which better enables INGOs to be accountable to the communities that they purport to serve.

\section{INGO Accountability Deficits}

INGOs are Northern-based civil society actors that are not principally defined by commercial motives and are 'geared to improving the quality of life for disadvantaged people' (Vakil, 1997: 2060). They are often categorised as either advocacy organisations or service providers, but recent years have witnessed a trend for the latter to become more cause-oriented (Lindeberg \& Bryant, 2001). The literature also sometimes elides the distinction between progressive and illiberal INGOs. It has frequently been observed that civil society enthusiasts tend to assume the altruistic motives of INGOs and their positive contribution to public life (Anderson \& Reiff, 2004). This paper focuses exclusively on Northern-based organisations that endorse politically and socially progressive norms, that have a particular interest in the welfare of peoples in the global South, and that aim to promote societal change. These INGOs incur profound accountability responsibilities towards peoples that are most affected by their activities and sense of mission. Moreover, it seems reasonable to presume that these organisations have a stake in critically reflective accountability practices orientated towards societal transformation.

INGOs have been portrayed as a 'magic bullet' in neoliberal discourse for a gamut of social and political problems (Edwards \& Hulme, 1996). It is argued that they are better skilled and more capable and efficient at delivering welfare services than state providers (Lewis, 2007: 41) - albeit this claim can often be read as an attempt to justify cutbacks, rather than a true reflection of INGO competence. INGOs have been encouraged to compensate for the retrenchment of government provision, and have been privileged as a conduit of aid by international development donors. They provide essential services for countless millions, in developed countries as well as the most desperate and dangerous environments. It has been estimated that INGOs distribute at least $\$ 7$ billion each year, exceeding the amount dispensed by the UN (Keane, 2003: 8).

INGO political authority is bolstered by public opinion. They are the most trusted institutions worldwide, in comparison to government, media and business (Edelman, 2011). Nonetheless, it cannot be assumed that the public will continue to hold INGOs in high regard. Unease has been 
expressed in some quarters that their increasingly assertive use of soft power is not being sufficiently matched with observance of the demands of political responsibility (Gibelman \& Gelman, 2001). Some of the most well-known INGOs have come under fire for poor performance and lack of transparency; such as Nature Conservatory, the biggest environmental INGO in the world, which attracted an avalanche of media and congressional criticism for questionable financial practices (Birchard, 2005). The Lancet recently provoked media attention by publishing a scathing editorial about the performance of INGOs in Haiti. It claimed that 'humanitarianism is no longer the ethos for many organisations in the aid industry', and that INGOs were 'obsessed with raising money' and 'media coverage as an end in itself', rather than the best interests of earthquake survivors (2010). High profile NGOs are at least partly accountable by reputational damage through bad publicity. Plenty of smaller NGOs operate below the 'media radar' but are no less susceptible to malpractice and mismanagement, as illustrated by the sexual abuse of children by aid workers (Csáky, 2008) and the chaotic relief effort in Indonesia following the 2004 tsunami (IFRC, 2005).

Misgivings have also been expressed about whether INGOs are capable of representing marginalised peoples when they are typically staffed by an elite; in Scholte's words, 'middle-aged adults, professional and propertied classes, men, Northern countries, whites, Christian heritages, and urban dwellers.' (2002: 296) The gulf in backgrounds and lived experiences may partly explain why representations of the 'needy' in INGO literature can be insensitive and demeaning - ironically compounding the disenfranchisement of the people it portrays (Nyamugasira, 1998). Smillie has criticised 'highly competitive fund-raising appeals, unsubstantiated INGO claims and unremitting horror stories from the South' for leading to more public ignorance in the North and 'a growing antipathy toward any kind of aid but for the most heart-wrenching plights.' (1996: 188)

Persistent tales of incompetence and impropriety will corrode the moral capital of INGOs - their prime source of political legitimacy. It is in the interest of the whole sector to engage with the drive for accountability to ward against the 'contagion effect', whereby a scandal involving a 'rogue' INGO precipitates a crisis of confidence that contaminates the reputation of others that are blameless. INGOs have a moral imperative, as ostensibly conscience-driven organisations, to strive to meet the highest standards of probity. An accountability regime has slowly emerged in recent years that aims to address this challenge. NGO accountability is defined in an oft-cited article as the process by which an NGO holds itself openly responsible for what it believes, what it does and what it does not do in a way which shows it involving all concerned parties and actively responding to what it learns.' (Slim, 2002, original emphasis)

INGOs have not always engaged with the accountability agenda of their own volition. Jordan observes that 'most NGOs address the issue of accountability when the political space within which they operate is somehow under threat.' (2007: 155) Self-regulation is a useful tactic to evade the threat of government-imposed regulation, which appeared to be the impetus for the establishment of NGO associations in Kenya, India, and Uganda (ibid.). INGO accountability mechanisms are also frequently introduced in response to donor demands. In both instances, INGO actions are motivated by strategic needs to placate governments and donors to protect their autonomy from external regulation and maintain their funding base. This reactive approach may appear to promote organisational survival, but it paradoxically undermines the most important component of INGO accountability: the primacy of those closest to their mission'.

This paper contends that INGOs must resist the 'capture' of the accountability agenda by powerful stakeholders. They should make proactive efforts to shape accountability discourse and practise in accordance with the needs and desires of the communities that they aim to serve, which at times might conflict with the expectations of donors and governments. The values at the heart of the mission should consistently supersede other demands; otherwise it will be difficult for INGOs to maintain their integrity. The overriding aim of INGO accountability mechanisms should be to 
encourage critical reflection on the organisation's role in promoting societal transformation (Ebrahim, 2007). This can only be achieved if accountability practice is primarily driven by dialogue with those most affected by their actions. INGOs need to secure authentication of their advocacy strategy and assess the quality of their service provision through consultation with the grassroots, and ensure that they recognise and learn from their failings. Although many INGOs profess to adopt such an approach, this paper argues that a meaningful cultural shift has not been fully realised due to countervailing pressures and attitudinal factors.

An overview of key drivers of the accountability agenda follows, which in recent years has resulted in two waves of reforms. The terms of the debate range from an accountability culture heavily influenced by standards imported from the business sector, to a more reflective approach that prioritises the expressed preferences of communities. This is a broad thematic summary of prevailing trends across leading INGOs. The structure and content of the analysis is represented by the table below. It must be stressed that INGOs are hugely diverse in their governance, strategy, operating procedures, geographical reach, size and resources, and not all have progressed in the same direction at the same rate.

\begin{tabular}{|c|c|c|c|}
\hline & Type of accountability & Main stakeholder/s & Characteristics \\
\hline \multirow[t]{3}{*}{$\begin{array}{l}\text { First Wave } \\
\text { Accountability }\end{array}$} & Fiscal & Donors & \multirow{3}{*}{$\begin{array}{l}\text { Accountability narrowly- } \\
\text { conceived. } \\
\text { Shaped by short-term, } \\
\text { campaign-specific targets. } \\
\text { Effectuated by significant } \\
\text { penalties for non- } \\
\text { compliance. }\end{array}$} \\
\hline & Legal & Governments & \\
\hline & Commission & Commissioning agent & \\
\hline \multirow[t]{3}{*}{$\begin{array}{l}\text { Second Wave } \\
\text { Accountability }\end{array}$} & Dialogic (external) & $\begin{array}{l}\text { 'Beneficiaries', } \\
\text { partners. }\end{array}$ & \multirow{3}{*}{$\begin{array}{l}\text { Accountability broadly- } \\
\text { conceived. } \\
\text { Aspires to long-term vision } \\
\text { of social change. } \\
\text { Espouses commitment to } \\
\text { participatory decision- } \\
\text { making and organisational } \\
\text { learning. }\end{array}$} \\
\hline & Dialogic (internal) & $\begin{array}{l}\text { Members, } \\
\text { staff. }\end{array}$ & \\
\hline & Peer & Peer INGOs & \\
\hline
\end{tabular}

\section{The First Wave of Accountability Reform}

The first wave of accountability reforms aimed to strengthen INGO governance by improving legal compliance and delivering good financial management. It was primarily focused on the right of donors - whether governmental, corporate, institutional or individual - to demand transparency about the expenditure and investment of funds. Greater efforts were made to provide information about how donations were linked to narrowly-defined campaign outcomes (narrowly-defined because the outcomes were not designed with meaningful consultation with grassroots communities, as discussed below). Most major INGOs now make their financial reports accessible to the wider public through their websites. This can be categorised as fiscal accountability. Fiscal accountability tends to be heavily embedded in INGO governance; largely because it is underpinned by the sanction of the withdrawal of funds if donors are not satisfied with the disclosure of information. 
INGOs are also obliged to be accountable to political authorities in the territories within which they operate. Legal accountability mainly applies to the domestic sphere, and so is varied in design and application. NGOs in some states are required to abide by specific criteria in order to access certain privileges. For example, the Philippine government only grants tax-deductable status for donations that have been accredited by the Philippines Council for NGO Certification for meeting minimum standards of fiscal transparency and accountability. The Council provides training, capacity-building workshops and resources to help embed improvements in accountability practices, which has helped to raise sector-wide standards in a country once notorious for endemic corruption amongst nonprofits. Legal accountability also has invidious effects. Some government-sponsored regulatory initiatives have been accused of being politically-motivated assaults on advocacy organisations (Jordan \& Van Tuijl, 2007) that inhibit activists from straying from mainstream discourse. There is also evidence that the implicit threat of increased regulation deters INGOs from being candid about their failings and pursuing reform efforts. In a survey of environmental INGOs, Jepson found that CEOs were apprehensive to open up the debate about accountability in case it would tempt governments to 'respond with knee-jerk, one-size-fits-all regulations that will not do anyone any good.' (2005: 517) The potential penalties for non-compliance are sufficiently grave to ensure that legal accountability is strong constraint on INGO behaviour.

The first wave also encompassed efforts to improve commission accountability, meaning the expectation that INGOs will be answerable to agents that have commissioned them to execute a task. It differs from fiscal accountability in that the INGO bears responsibilities to the commissioning agent, who does not necessarily have to be a donor. Moreover, the boundaries of commission accountability are defined by the commissioned task, whether paid for or not; whereas fiscal accountability encompasses donations without conditions attached. The extant literature on INGO accountability tends to overlook these important distinctions between the source of an organisation's funds." The commissioning agent is typically a local/national government or multilateral institution, such as the IMF or World Bank. In addition, large businesses can task an INGO to audit their corporate social responsibility practices, such as Social Accountability Accreditation Services and the Fair Labor Association. INGOs will be expected to produce a written report at the conclusion of a project, and often interim reports whilst the project is in progress. Possibilities of being granted future contracts will be damaged if the INGO is found to perform poorly, as will the professional perception of the INGO as efficient and reliable. The norms of commission accountability therefore also tend to be strongly institutionalised in INGO governance.

First wave accountability mechanisms, then, have thematic similarities. They are engineered to satisfy the demands of powerful stakeholders. They are focused on tracking the use of resources, and preoccupied with campaign-specific, short-term targets. INGO performance is recorded and assessed by experts using quantitative methodologies, and documentation is produced for the consumption of the highly literate, who are well-versed in financial jargon and policy terminology. The advances of the first wave were essential to help establish the credentials of INGOs as actors of probity. However, it emulates a corporate model of accountability that is not always congruent with the core norms that distinguish INGOs from other private actors. It does not fully incorporate the responsibilities of the INGO to be mindful and responsive to the concerns of the people closest to their mission, which supposedly are the organisation's raison d'être.

Moreover, first wave accountability discourages the evolution of the INGO as a learning organisation. INGOs often conduct highly complex operations that present intimidating logistical challenges. A humanitarian relief operation in the aftermath of a natural disaster, for example, will require the transport and deployment of foodstuffs, housing materials, medical supplies and aid workers within a short time-frame. A multitude of errors can occur in such chaotic circumstances: there may be unforeseen delays in aid delivery, fieldworkers may miscalculate the extent of need, food may become contaminated, and so on. However, the 'adrenalin culture' that develops under 
pressure to demonstrate results to donors is not conducive to open discussion of failure (Britton, 2005: 6). The potential repercussions inhibit INGOs 'from publishing or even sharing lessons learned from programme experience.' (ibid.) INGOs are instead rewarded for conforming (or appearing to conform) to narrowly-defined benchmarks that reflect the preferences of powerful stakeholders who can impose financial and legal sanctions on the organisation. INGOs have a perverse incentive to gloss over their mistakes and avoid critical self-reflection on performance.

Practitioners and academics helped to raise awareness of these issues, which helped to generate a second wave of reforms. The beginnings of this shift can be traced to the period of soul-searching amongst humanitarian INGOs that followed the botched relief operation during the 1994 Rwandan conflict (Slim, 2002). It is worth restating that different INGOs have followed the reform trajectory at different stages. Change across the sector is still ongoing and has thus far been incremental and fragmentary.

\section{The Second Wave of Reform}

The second wave of reforms is a departure from a narrowly-conceived notion of accountability to a holistic perspective on accountability relationships. INGOs are held primarily accountable to their intended 'beneficiaries' - the standard term for the individuals and communities that INGOs aim to represent and serve. They also bear duties to staff, members, and peer INGOs. The second wave is not a wholesale rejection of the first wave model. Financial, legal and commission accountability are basic elements of good governance. Rather, it reclaims the mission by rebalancing accountability relationships in favour of the least powerful stakeholders. Second wave accountability is designed to further the strategic objectives of the INGO as an agent of social change; however, it largely remains at the stage of widely-espoused aspirations, rather than widely-observed practice.

The second wave is inspired by the notions of 'people-centred development' (Korten, 1983), community empowerment and participatory decision-making. These once radical ideas are now touted by institutions such as the World Bank and the OECD, and have become part of development orthodoxy. INGOs such as Oxfam and ActionAid have taken the lead in the sector in designing and implementing participation techniques amongst beneficiaries (Bryant, 2007; Jordan, 2007). Beneficiary participation in the decision-making process is facilitated at various levels, ranging from consultations with community leaders, to focus groups and village assemblies. Participatory research methodologies, such as social mapping, timelines and 'well-being' ranking are used to broaden and deepen involvement amongst communities with poor rates of literacy (Narayanasamy, 2009). The aim is to maximise inclusivity and enfranchise the most marginalised peoples, who usually have little if any input into decisions that affect their lives. These various participatory initiatives can be grouped under the term dialogic accountability. The views of beneficiaries help to shape the formulation of INGO policy, and to monitor and evaluate impacts and outcomes. INGOs can also promote their mission of long-term societal transformation by empowering and enabling people to articulate their demands and collaborate to achieve mutual goals. These skills can help to foster community self-reliance, which will reap dividends beyond the short-term, campaign-specific objectives of the INGO. Dialogic accountability conveys the intention that an INGO and its beneficiaries should be nominal equals in debate, despite the obvious power differentials in the relationship. It is a preferable term to the more commonly used 'downwards accountability', which can be seen as implying a unidirectional flow of communication from INGOs to beneficiaries. Dialogic accountability helps to reinforce the norm of reciprocity in dialogue, and the responsibility of the INGO to be a responsive interlocutor. It is also preferable to the notions of 'voice' and 'exit' accountability (Ebrahim, 2003b: 200, 204), which restricts the rights of the community to make complaints or to simply 'walk away'. Dialogic accountability, in contrast, encourages mutual learning and critically reflective practice. In reality, this aspiration is not translated into practice, because the 
stark disparity of socio-economic status between both parties often distorts the conditions for frank and constructive discussion (as discussed in more detail below).

Second-wave reforms encourage INGOs to embrace failure, as long as lessons are learned to prevent the recurrence of mistakes. Beneficiary feedback should assist in diagnosing the causes of organisational failure, finding remedies and improving future practice. This is particularly challenging to achieve given as INGOs are rather insulated from compelling pressures that prompt change in the public and private sector (Ronalds, 2010: 181). Businesses are beholden to their shareholders and their consumers. It is easy for the former to evaluate profit-reports, and for the latter to compare the quality of products from rival suppliers. It is not so straightforward for INGO donors to determine if money is being invested in ways that adhere to the mission, because information may be scarce, and measurement of societal impact is notoriously difficult (Oakley, et al., 1998). Similarly, elected politicians are expected to be routinely answerable for their actions, and governments can be removed from office if the public vote them out. Beneficiaries, in contrast, may have few alternatives to the services that the INGO provides, and so it is difficult for them to express dissatisfaction by 'voting with their feet'. INGOs are not subject to popular checks and balances, even if they assume quasi-governmental functions. Organisational learning is therefore largely dependent upon the willingness of the INGO to be candid about failings, to invite criticism and external scrutiny and to be self-reflective about performance. The second-wave approach encourages INGOs to be proactive in facilitating external dialogic accountability, even if the beneficiaries deliver opinions that do not redound to the INGOs' credit. This may be considered rather ambitious in the context of intense competition for donor resources.

External dialogic accountability extends to relationships with local partners. Many development INGOs have shifted from direct project-implementation to pursuing partnership with Southern NGOs; for instance, by providing financial support for capacity-building projects (Lewis, 2007: 184). Partnership is popular with bilateral donors, as it is portrayed in development discourse as an important element of aid-effectiveness and beneficiary-empowerment (ibid: 185). Although 'partnerships' imply some degree of mutuality, they are often asymmetrical. INGOs 'have the power of funding but also of global knowledge networks and superior communication channels that make them feared competitors of local NGOs; their power is often used to set the terms and conditions of funding and accountability for their partners.' (Wallace, et al, 2006: 4-5) Elbers and Arts find that Southern NGOs sometimes adopt strategic behaviour to evade the undesirable consequences of conditions attached to INGO funds, such as manipulating perceptions of compliance (2011). The principles of second wave accountability are thus significantly undermined. Nevertheless, there are some good examples of meaningful discourse and mutual learning in the sector (Gaventa, 2004). The ICCO in the Netherlands has sought to institutionalise partnership by establishing Regional Councils in Africa, Asia and the Americas, which contribute towards policy development. Formal structures for policy dialogue, however, remain rare (Brehm, 2001). Dialogic accountability also applies to internal INGO relationships. A recent survey of officials from a broad range of INGOs found that accountability responsibilities to the membership are prioritised by $40 \%$ of respondents (Piewitt et al., 2010: 245). The internet has enabled INGOs to reach out to members by providing more information about their activities than ever before. Even NGOs with a relatively small resource-base usually sustain a decent website, email distribution list, Facebook page and Twitter feed, all of which have the inherent potential to elicit dialogue. Research indicates, however, that Web-based platforms tend to be used more for disclosure of financial and performance data, rather than foster meaningful communication with members and other stakeholders (Saxton \& Guo, 2011). This partly reflects depressed demand. Case study evidence suggests that members do not covet a greater role in decision-making (O'Dwyer \& Unerman, 2008: 813).

Internal dialogic accountability extends to management-staff relations. INGOs are structured along hierarchical divisions of line management that characterise any bureaucratic organisation. Tasks are 
delegated and staff members are accountable to their line managers for their delivery. Performance appraisals are routine. The senior management team are held accountable to the Board. The latter are chosen through election or via a Nominations Committee, and are removable if they contravene codes of conduct. In a survey of leaders from over 150 NGOs, Schmitz et al found that these relations of accountability are accorded wide respect in the sector (2011: 10). Over half of the respondents identified themselves as accountable to the Board, and over a fifth as accountable to staff.

The final strand of second wave reforms is peer accountability, which refers to voluntary regulatory regimes that are populated and financed by INGOs, and are typically administered by an independent third party. Peer-regulation regimes emerged in the wake of the furore about the infiltration of militia in Rwandan refugee camps (Storey, 1997). Initiatives such as the Sphere Project and the Humanitarian Accountability Partnership were designed to encourage INGOs to establish consensus about minimum standards and to engage in cross-sectoral dialogue about best practice. The regimes range from broadly defined codes of conduct with weak oversight, to formal certification schemes with scrupulous reporting requirements. Peer-regulation has helped to sponsor a multi-stakeholder approach to accountability; however, Lloyd and de las Casas find that with some honourable exceptions, most peer-regulation regimes describe beneficiary accountability in an ambiguous way. They argue that this 'vagueness makes implementation and enforcement difficult, and contrasts with the level of detail relating to financial management, reporting and public disclosure.' (2006: 4)

Second wave accountability is weakly institutionalised in INGO governance, partly because the sanctions for non-compliance are not as direct or coercive as those associated with the first wave. Dialogic accountability is difficult to sustain when beneficiaries are highly dependent on INGOs, and so probably inhibited from speaking with candour. The membership is largely indifferent about the intricacies of policy, and so INGOs can avoid scrutiny by communicating through superficial 'feel good' PR literature that does not encourage deeper engagement with governance. Staff-members could resign if they were dissatisfied with the INGOs' standards of accountability; but this is less likely once people have become socialised into institutional norms. Further, peer-regulation regimes have little public visibility and sometimes little practical application, and so could be accused of merely being an elitist preoccupation (Crack, 2012).

Nonetheless, the second wave is a welcome departure from the target-obsessed, managerialist tenor of the first wave. It has helped to entrench the norm that beneficiary involvement is a hallmark of good governance for progressive INGOs. Yet too often second wave rhetoric can fail to resemble the reality of accountability practice. The 'elephant in the room', according to Edwards, is that the pressure on INGOs to respond to economic imperatives and the preferences of powerful stakeholders usually prevails over the norms that are championed about accountability to people and communities (2008: 49; also Wallace et al., 2006).This paper contends that INGOs need to undertake more radical reform to achieve a deep-seated shift in accountability culture. Three thematic areas for change must be addressed if INGOs are to become truly mission-led organisations: the language of accountability, and the listening and learning capacity of the INGO.

\section{Language: Framing Dialogic Accountability}

Meaningful dialogic accountability is predicated on parties that are nominal equals in debate, notwithstanding differences in socio-economic status. In reality, public deliberation is structured by gross social inequalities that curtail the capacity of subordinate groups to articulate their grievances (Crack, 2008: 32-33). The disparity is evident in the reification of hierarchical relationships in accountability discourse. The very word, 'beneficiary', speaks volumes about how debates and 
agendas are framed in subtle ways that favour INGO interests and interpretations. It presupposes that people and communities will assuredly benefit from INGO activities, and delegitimises alternative narratives about their unhelpful and harmful effects. The tacit assumption that INGOs are positive agents of change relieves them of the responsibility to provide robust evidence that their activities have benign impacts. The discourse is couched in terms that implicitly inoculate the INGO from criticism, even if these effects are unintended by well-meaning proponents who proclaim a strong attachment to the mission. Thus, ostensible efforts to enhance accountability are fundamentally undermined.

Another insidious effect of the word 'beneficiary' is that it may reinforce the perception of INGOs as neo-colonial agents. It has almost missionary connotations, and is suggestive of a hubristic and paternalistic attitude. It evokes an image of practitioners who are smug about their supposed benevolence, complacent about the value of philanthropy and who anticipate gratitude from the recipients. Moreover, the imposed identity of 'beneficiary' disempowers people and communities by implying passivity and emphasising neediness. A change in the standard terminology of the sector is needed to mirror the change in mind-set that was supposed to be inculcated by the second wave.

The term primary stakeholderii better reflects the sense that INGO accountability and legitimacy is chiefly dependent upon its relationship with the people and communities that it claims to represent and serve. All other accountability relationships should be considered subservient to the responsibilities that the INGO incurs to primary stakeholders. The term also helps to restore respect for their autonomy and dignity. The sector should re-evaluate its use of language elsewhere and consider whether it is imbued with vestiges of false certainty about its beneficial impact. INGOs shouldf actively seek validation about the positive nature of their contribution to community life from the people they purport to help. The use of less pejorative language facilitates the listening process.

\section{Listening: Enabling Meaningful Participation}

The notion of 'participation' has totemic significance in second wave discourse. However, this can mean that participation is too frequently treated as an ends in itself. It is exceptionally challenging to enable meaningful discursive engagement because INGO relationships with primary stakeholders are often founded on deeply unequal terms. The increasingly professionalised INGO sector is largely staffed ${ }^{\text {iv }}$ by a well-educated, highly-skilled socio-economic elite (Smith \& Jenkins, 2011). Their lives are far removed from the realities of primary stakeholders. Senior staff are fully conversant with policy discourse, and their jobs will typically require that they routinely articulate their objectives in a persuasive way to multiple audiences, such as the public, the media, officials, and their colleagues. INGO staff also control the design of participatory exercises: they determine the research questions, the methodology, data collection and the representation of outcomes. Two potential problems arise as a consequence of this asymmetry in capacity and agenda-setting power.

First, staff may unintentionally misinterpret the contributions of primary stakeholders, because they are insufficiently sensitive to issues of power and cultural difference. Primary stakeholders may be loath to criticise INGOs because they are apprehensive about losing aid and services, particularly if they are highly dependent upon their support and there are few alternative providers. There is also evidence to suggest that 'members of poor communities sometimes lack the self-esteem to act assertively' (Burger \& Owens, 2010: 1264) and that they find it difficult to 'make their voices heard' in forums which are culturally biased against their vernacular and non-literate forms of expression. The problem is particularly acute for discriminated groups within communities, based on gender, disability, sexual preference, ethnicity, caste, and religious belief. Gujit and Shah have criticised the tendency to idealise the 'community' as cohesive and harmonious, since it conceals power relations 
and divergent interests (1998: 8). Marginalised groups live within political and social structures that limit their capacity for full and equal participation in decision-making. INGOs could compound these discriminations if they make poor choices of participants in consultation exercises. They should certainly not uncritically accept the views of professed 'community leaders' as representative of wider feeling in the community. However, mere equitable representation of sub-community groups is not sufficient for inclusive dialogue. Consultations need to be carefully designed to create a space where participants are equally enabled and empowered to articulate their concerns. Research has consistently shown, for example, that there are significant gender differences in contributions to exercises that superficially appear to be participatory (ibid.).

Second, it might be in the self-interest of staff to misrepresent the views of primary stakeholders if they cast the INGO in an unflattering light. Negative feedback could potentially damage future fundraising prospects, and have professional consequences for under-performing staff-members. INGOs need to be sensitive to the potential disjuncture between the normative aspirations of the mission and the conditions that promote organisational survival. This demands critical reflection on difficult ethical questions about the extent to which INGOs are dependent upon the dependence of primary stakeholders, notwithstanding mission rhetoric about empowerment and self-reliance. INGOs have been criticised for 'franchising global brands instead of supporting authentic expressions of indigenous civil society, and crowding out Southern participation in knowledge-creation and advocacy in order to increase their own voice and profile.' (Edwards, 2008: 47) INGOs could be seen to have an interest in curbing the voices and activism of primary stakeholders in order to protect their 'turf'. There are risks that processes that are nominally participatory are framed in a way to elicit findings that validate the self-perception of the INGO as a necessary presence. INGO staff may therefore effectively 'police' the boundaries of participation, but not necessarily in premeditated way. On the contrary, it may occur through unconscious behaviours by well-meaning individuals who have not been trained in critical reflective practice.

Covert agendas can thus render 'participation' as little more than a façade that lends a misleading aura of authenticity to decisions that are actually taken in a top-down, exclusionary manner. The tension between two parties in a profoundly unequal relationship cannot be entirely eradicated. The effects can be mitigated, however, and an important first step is for staff to disabuse themselves of naïve belief that participation is a panacea for primary stakeholder accountability. The organisation should actively engender debate about practical ways to ensure that it is more inclusive and receptive to stakeholder feedback, which should involve community consultation and researchers trained in participatory methodologies. Each staff-member should also be obliged to undertake periodic critical reflection on these issues. Tools could be developed to encourage staff to map out the multidimensionality of power relations and to reflect upon their own role in navigating, and perhaps unintentionally reproducing, these power disparities. The well-managed INGO will ensure that processes of listening and reflection are translated into organisational learning for improved practice.

\section{Learning: Completing the Feedback Loop}

A highly competitive funding environment provides perverse incentives for INGOs to be defensive about their shortcomings, rather than embrace honest assessments of their performance and seek remedial strategies. Instances of failure actually present the most valuable opportunities for critical self-reflection and organisational learning. Britton reports that this potential for growth is not being successfully exploited across the sector; indeed, 'many NGOs admit that they suffered from a lack of organisational memory that bordered on clinical amnesia.' (2005: 7) There is little point in listening to feedback unless it is mobilised to diagnose the reasons for failure and to leverage change. INGOs need management procedures in place to induce staff to respond to feedback, but such a profound 
cultural shift in accountability practice is unlikely to be achieved without external pressure. Burger and Owens warn that their findings 'caution against an over-reliance on reported information when regulating, monitoring, or surveying NGOs. They also emphasize the value of third-party monitoring and regulation.' (2010: 1274) Independent evaluation of INGO performance needs to be enhanced through strengthened peer-regulation regimes, and sufficiently strong sanctions put in place for serious non-compliance. Even regulation mechanisms that have rigorous reporting requirements, like the INGO Accountability Charter, do not contain provisions for complaints and redress. Greater use could be made of volunteer ombudsmen in this respect, perhaps drawing on independent academic experts, or renowned practitioners in retirement who are not seen to have a vested interest in adjudication.

Sanctions should be deployed judiciously, or peer accountability will not foster an atmosphere of greater openness. INGOs guilty of grievous misconduct should face some form of reprimand to uphold public confidence in the integrity of peer-regulation. However, regulators have a role to play in educating donors about likelihood of failure in the kinds of high-risk environments where INGOs operate. They could also positively reinforce 'good behaviour' by commending INGOs that represent the best examples of organisational learning. Perhaps the introduction of a 'gold standard' award could help to raise aspirations across the sector for better practice. NGOs that win the prize could be granted the right to display a symbol of the award in their campaigns literature. It would help INGOs to sustain their funding base by burnishing their accountability credentials to their donors, and also contribute to the greater good of raising public awareness about peer-regulation.

Insular attitudes are one of the greatest obstacles to critical self-reflection and organisational learning. Coates and David have detailed the 'obsession of many NGOs with assessing the impact of their own organisation in isolation from others.' (2002: 534) They argue that '[w]hile this may be important for institutional profile, such measures can encourage competitive rather than collaborative behaviour, providing incentives for campaigners to elevate their own profile over others...' (ibid.) This might be remedied by supplementing formal peer accountability with networking opportunities. INGOs could extend reciprocal invitations to staff from peer INGOs to attend events such as policy meetings, AGMs and primary stakeholder participatory exercises. The sector has also been slow to exploit the networking potential of the internet. Launched in January 2011, Admittingfailure.com aims to address this gap by encouraging honest accounts of underperformance from development professionals in a spirit of transparency and mutual learning. Even the most informal interactions may help staff to internalise norms of accountability, and so assist transformation in accountability culture.

Critically reflective accountability is fraught with intimidating challenges, but it is not hopelessly unrealistic. ActionAid have been at the forefront of important innovations in critically reflective practice that are widely admired by other humanitarian and development agencies. Their 'Action, Learning and Planning System' (ALPS) is designed to explicitly privilege accountability to primary stakeholders at all stages of the policy process (ActionAid International, 2011). ALPS heavily emphasises organisational learning through a regular cycle of evaluation and appraisals conducted in partnership with local peoples. Rather than rely on standardised evaluation criteria, it draws largely upon rich personal testimonials and vignettes, which allow aid programmes to be judged in relation to the unique challenges posed by the local context. In communities where there is a high degree of illiteracy, data is gathered through creative participatory techniques such as drama, music and art. These consultations are rather demanding in scope, and potentially entail opportunity-costs in staff time and resources. However, ALPS avoids an overly-bureaucratic approach by devolving accountability responsibilities as much as possible to those closest to the ground (ibid.). Individual aid workers are required to personally reflect on how disparities of power impinge upon the NGOs' relationship with communities, in an attempt to prompt changes in attitudes and behaviours that help embed the principles of reflective accountability at all levels of the organisation. The 
introduction of ALPS has not been trouble-free (Scott-Villiers, 2002). It has been criticised for weak organisational development support, and concerns have been raised that progress is undermined by pressure from donors to demonstrate outcomes (David \& Mancini, 2004). Implementation of the programme has been uneven because some staff were ill-informed about the changes or failed to fully engage with the ALPS agenda (ActionAid, 2007). Nonetheless, ALPS has been commended in sector-wide surveys as representing excellent practice (Blagescu \& Lloyd, 2006: 8).

\section{Conclusion}

INGO accountability has undergone a metamorphosis over recent decades. There has been a gradual evolution from an accountability model narrowly framed around the demands of powerful stakeholders, to a more holistic approach that puts the rights of so-called 'beneficiaries' at the helm. This paper has aimed to contribute towards the theory of INGO accountability by proposing a typology for different relationships of accountability. It has introduced a category of 'commission accountability' to distinguish between funding sources - a distinction that tends to be collapsed or ignored in the extant literature. It has also sought to promote the principles of critically reflective accountability by introducing the concept of 'dialogic accountability', which emphasises the responsibility of the INGO to strive for maximal inclusivity in community consultations, and to be responsive to views that are aired. It has also suggested that INGOs should seek to embed critically reflective accountability through the three 'Ls'. Words like 'beneficiary' should be expunged from the language of accountability, since it is encoded with norms that implicitly undermine the rights of primary stakeholders to expect that INGOs should be answerable for their actions. Listening to marginalised primary stakeholders is facilitated by inclusive discursive arenas that enable and empower people 'to speak and be heard'. Further, INGOs need to use feedback to become a learning organisation, and collaborate with peers to engender a culture of reflective learning across the sector.

The risks inherent in critically reflective accountability should not be underestimated. Exposure of organisational failure is highly likely to lead to negative publicity, which could provide fodder for adversaries to launch political attacks that result in lasting reputational damage. Critically reflective accountability is labour-intensive. The time spent on eliciting primary stakeholder participation and evaluating performance could otherwise be spent on fundraising, advocacy or service delivery. Further, Bryant notes that INGOs may feel compelled to underplay the amount they spend on activities unrelated to their grassroots work: 'Those who want the greatest accountability...are not necessarily those private contributors writing their Christmas checks...It increases the overhead and annual appeals have to point to low, not rising overheads.' (2007: 180) It is worth reiterating that not all INGOs advocate socially and politically progressive goals, or exhibit interest in enhancing their accountability. Ironically, INGOs that shield their misdemeanours from the public gaze could profit in comparison with INGOs of greater integrity that are willing to brave the consequences of transparency.

The short-term risks of critically reflective accountability are arguably outweighed by the long-term investment in the ethical credibility of progressive INGOs. INGOs will be seen as disingenuous if they allow accountability to be distorted by the demands of powerful stakeholders; or if they exploit opportunities to court good publicity by overemphasising success. Progressive INGOs must endeavour to stay true to their mission by maintaining a robust defence of their moral capital. A deep-seated shift in accountability culture is achievable if the sector intensifies collaboration to raise standards and engender mutual learning. Critically reflective accountability could help endow progressive INGOs with the moral authority to promote societal transformation. 
I would like to thank the anonymous reviewers for their helpful feedback.

ActionAid (2007). ALPS Review. BOND Quality Group. http://quality.bond.org.uk/images/4/42/ALPS_REVIEW_2007_low_res.pdf

ActionAid International (2011). Action, Learning and Planning System. http://www.actionaid.org/sites/files/actionaid/alps2011 revised06july2011.pdf

Anderson, K. \& Reiff, D. (2004). Global Civil Society: A Sceptical View. In H. Anheier, M. Glasius \& M. Kaldor (eds) Global Civil Society 2004/5. London: Sage, 26-39.

Birchard, B. (2005). Nature's Keepers: The Remarkable Story of how the Nature Conservancy Became the Largest Environmental Group in the World. San Francisco, CA: Wiley.

Blagescu, M. \& Lloyd, R. (2006). 2006 Global Accountability Report. London: One World Trust.

Brehm, V. M. (2001) Promoting Effective North-South Partnerships. Occasional Papers Series no. 35. Oxford: INTRAC.

Britton, B. (2005) Organisational Learning in NGOs: Creating the Motive, Means and Opportunity. Oxford: INTRAC.

Bryant, C. (2007). Evaluation and accountability in emergency relief. In A. Ebrahim \& E. Weisband (Eds.), Global Accountabilities: Participation, Pluralism and Public Ethics. Cambridge: Cambridge University Press, 193-224.

Burger, R. \& Owens, T. (2010). Promoting Transparency in the NGO Sector: Examining the Availability and Reliability of Self-Reported Data. World Development, 38(9), 1263-77.

Coates, B. \& David, R. (2002). Learning for change: the art of assessing advocacy work. Development in Practice. 12(3/4), 530-541.

Collingwood, V. \& Logister, L. (2005). State of the Art: Addressing the INGO "Legitimacy Deficit". Political Studies Review, 3, 175-92.

Crack, A. M. (2012) The Effectiveness of INGO Peer-Regulation. Paper presented at the Annual Convention of the International Studies Association, San Diego.

Crack, A. M. (2008). Global Communication and Transnational Public Spheres. New York: Palgrave.

Csáky, C. (2008). No One to Turn To: The under-reporting of child exploitation and abuse by aid workers and peace-keepers. London: Save the Children UK.

David, R. \& Mancini, A. (2004). Going Against the Flow: the struggle to make organisational systems part of the solution rather than the problem. The case of ActionAid's Accountability, Planning and Learning System. Brighton: Institute for Development Studies.

Ebrahim, A. (2003a). Accountability in Practice: Mechanisms for NGOs. World Development, 31(5), 813-829.

Ebrahim, E. (2003b). Making Sense of Accountability: Conceptual Perspectives for Northern and Southern Nonprofits. Nonprofit Management and Leadership, 14(2), 191-211. 
Ebrahim, A. (2007). Towards a reflective accountability in NGOs. In A. Ebrahim \& E. Weisband (Eds.) Global Accountabilities: Participation, Pluralism and Public Ethics. Cambridge: Cambridge University Press, 193-224.

Edelman (2011). Edelman Trust Barometer Survey. http://www.edelman.com/trust/2011/

Edwards, M. (2008). Have NGOs "Made a Difference?" From Manchester to Birmingham with an Elephant in the Room. In Bebbington, A. J. et al. (Eds.) Can NGOs Make a Difference? The Challenge of Development Alternatives. London: Zed Books, 38-52.

Edwards, M. \& Hulme, D. (Eds.). (1996). Beyond the Magic Bullet: NGO Performance and Accountability in the Post-Cold War World. Bloomfield, CT: Kumarian Press.

Elbers, W. \& Arts, B. (2011) Keeping body and soul together: southern NGOs' strategic responses to donor constraints. International Review of Administrative Sciences, 77(4), 713-32.

Gaventa, J. (2004) Crossing the Great Divide: Building Links and Learning Between NGOs and Community-based Organisations in the North and South. In Edwards, M. \& Fowler, A. (Eds.) The Earthscan Reader on NGO Management. Oxford: Earthscan, 256-74.

Gibelman, M., \& Gelman, S. R. (2001). Very public scandals: Nongovernmental organizations in trouble. Voluntas, 12(1), 49-66.

Gujit, I. \& Shah, M. K. (Eds.). (1998). The Myth of Community: Gender Issues in Participatory Development. London: ITDG Publishing.

IFRC. (International Federation of Red Cross and Red Crescent Societies). (2005). World Disasters Report 2005: Focus on Information in Disasters. Geneva: IFRC.

Jepson, P. (2005). Governance and Accountability of Environmental NGOs. Environmental Science \& Policy, 8, 515-24.

Jordan, L. (2007). A rights-based approach to accountability. In A. Ebrahim \& E. Weisband (Eds.) Global Accountabilities: Participation, Pluralism and Public Ethics. Cambridge: Cambridge University Press, 151-167.

Jordan, L. \& van Tuijl, P. (2000). Political Responsibility in Transnational NGO Advocacy. World Development, 28(12), 2051-2065.

Keane, J. (2003). Global Civil Society? Cambridge: Cambridge University Press.

Kilby, P. (2006). Accountability for Empowerment: Dilemmas Facing Non-Governmental Organizations. World Development. 34(6), 951-963.

Korten, D. C. (1984). Strategic Organization for People-Centered Development. Public Administration Review, 44(4), 341-352.

Lewis, D. (2007) The Management of Non-Governmental Development Organizations. London: Routledge.

Lindenberg, M. \& Bryant, C. (2001). Going Global. Transforming Relief and Development NGOs. Bloomfield, CT: Kumarian Press.

Lloyd, R. \& de las Casas, L. (2006). NGO self-regulation: enforcing and balancing accountability. London: One World Trust. 
Lloyd, R, Warren, S. and Hammer, M. (2008). Global Accountability Report. London: One World Trust. Mathews, J. (1997). Power Shift. Foreign Affairs. 76: 50-66.

Narayanasamy, N. (2009). Participatory Rural Appraisal: Principles, Methods and Application. New Delhi: Sage.

Nyamugasira, W. (1998). NGOs and Advocacy: How Well are the Poor Represented? Development in Practice. 8(3), 297-308.

Oakley, P., Pratt, B. \& Clayton, A. (1998). Outcomes and Impact: Evaluating Change in Social Development. Oxford: International NGO Training and Research Centre.

O'Dwyer, J. \& Unerman, J. (2008). The paradox of greater NGO accountability: A case study of Amnesty Ireland. Accounting, Organizations and Society, 33, 801-824.

O'Dwyer, B. \& Unerman, J. (2010). Enhancing the role of accountability in promoting the rights of beneficiaries of development NGOs. Accounting and Business Research. 40(5), 451-71.

Piewitt, M., Rodekamp, M. \& Steffek, J. (2010). Civil Society in World Politics: How Accountable are Transnational CSOs? Journal of Civil Society, 6(3), 237-58.

Ronalds, P. (2010). The Change Imperative: Creating the Next Generation NGO. Sterling, VA: Kumarian Press.

Saxton, G. D, \& Guo, C. (2011). Accountability Online: Understanding the Web-Based Accountability Practices of Nonprofit Organizations. Nonprofit and Voluntary Sector Quarterly, 40(2), 270295.

Schmitz, H. P., Raggo, P. \& Vijfeijken, T. B. (2011). Accountability of Transnational NGOs: Aspirations vs. Practice. Nonprofit and Voluntary Sector Quarterly, X(XX), 1-20.

Scholte, J. A. (2002). Civil Society and Global Governance. Global Governance, 8(3), 281-304.

Scott-Villiers, P. (2002). The struggle for organisational change: How the ActionAid Accountability, Learning and Planning System emerged. Development in Practice, 12(3), 424-35.

Slim, H. (2002) By What Authority? The legitimacy and accountability of non-governmental organizations. The International Council on Human Rights Policy. www.ichrp.org/paper files/119 w 02.doc.

Smillie, I. (1996). Painting Canadian Roses Red. In Edwards, M. \& Hulme, D. (Eds.) Beyond the Magic Bullet: NGO Performance and Accountability in the Post-Cold War World. Bloomfield, CT: Kumarian Press, 187-197.

Smith, M. B. \& Jenkins, K. (2011). Disconnections and exclusions: professionalization, cosmopolitanism and (global?) civil society. Global Networks, 11(2), 160-179.

Storey, A. (1997). Non-Neutral Humanitarianism: NGOs and the Rwandan Crisis. Development in Practice, 7(4), 384-394.

The Lancet. (2010). Growth of Aid and the Decline of Humanitarianism. 375(9711), 253. 
Vakil, A. (1997). Confronting the classification problem: towards a taxonomy of NGOs. World Development, 25(12): 2057-71.

Wallace, T., Bornstein, L. \& Chapman, J. (Eds.) (2006) The Aid Chain: Coercion and Commitment in Development NGOs. Rugby: Intermediate Technology Publications.

\footnotetext{
'The 'mission' is the fundamental strategic objective of the organisation.

ii For example, Ebrahim (2003b) separates NGOs stakeholders into three primary groups: sector regulators, clients and communities, and 'funders'. Although he admits that this is a deliberate simplification, I argue that the latter category is too broad to be analytically useful, and introduce the concept of 'commission accountability' as a corrective. It is worth also noting that Ebrahim's model of accountability does not recognise crucial actors such as staff-members and peer and partner organisations.

iii A small number of INGOs such as Oxfam and Care International refer to 'primary stakeholders' in their literature, but even here it is still used interchangeably with the standard term of 'beneficiaries'.

iv 'Staff' encompasses paid and unpaid personnel.
} 